\title{
Suitability of external controls for drug evaluation in Duchenne muscular dystrophy
}

Nathalie Goemans, MD, James Signorovitch, PhD, Gautam Sajeev, ScD, Zhiwen Yao, BA, Heather Gordish-Dressman, PhD, Craig M. McDonald, MD, Krista Vandenborne, PhD, Debra Miller, BA, Susan J. Ward, PhD, and Eugenio Mercuri, MD, for the investigators from PRO-DMD-01 Study, CINRG DNHS, ImagingDMD, and the DMD Italian Group

Neurology ${ }^{\circledR}$ 2020;95:e1381-e1391. doi:10.1212/WNL.0000000000010170

\section{Abstract \\ Objective}

To evaluate the suitability of real-world data (RWD) and natural history data (NHD) for use as external controls in drug evaluations for ambulatory Duchenne muscular dystrophy (DMD).

\section{Methods}

The consistency of changes in the 6-minute walk distance $(\Delta 6 \mathrm{MWD})$ was assessed across multiple clinical trial placebo arms and sources of NHD/RWD. Six placebo arms reporting 48week $\triangle 6 \mathrm{MWD}$ were identified via literature review and represented 4 sets of inclusion/exclusion criteria ( $\mathrm{n}=383$ patients in total). Five sources of RWD/NHD were contributed by Universitaire Ziekenhuizen Leuven, DMD Italian Group, The Cooperative International Neuromuscular Research Group, ImagingDMD, and the PRO-DMD-01 study ( $\mathrm{n}=430$ patients, in total). Mean $\triangle 6 \mathrm{MWD}$ was compared between each placebo arm and RWD/NHD source after subjecting the latter to the inclusion/exclusion criteria of the trial for baseline age, ambulatory function, and steroid use. Baseline covariate adjustment was investigated in a subset of patients with available data.

\section{Results}

Analyses included $\sim 1,200$ patient-years of follow-up. Differences in mean $\triangle 6 \mathrm{MWD}$ between trial placebo arms and RWD/NHD cohorts ranged from $-19.4 \mathrm{~m}$ (i.e., better outcomes in $\mathrm{RWD} / \mathrm{NHD}$ ) to $19.5 \mathrm{~m}$ (i.e., worse outcomes in RWD/NHD) and were not statistically significant before or after covariate adjustment.

\section{Conclusions}

We found that $\triangle 6 \mathrm{MWD}$ was consistent between placebo arms and RWD/NHD subjected to equivalent inclusion/exclusion criteria. No evidence for systematic bias was detected. These findings are encouraging for the use of RWD/NHD to augment, or possibly replace, placebo controls in DMD trials. Multi-institution collaboration through the Collaborative Trajectory Analysis Project rendered this study feasible.

\author{
Correspondence \\ Dr. Mercuri \\ eugeniomaria.mercuri@ \\ unicatt.it
}




\section{Glossary}

CINRG $=$ The Cooperative International Neuromuscular Research Group; cTAP = collaborative Trajectory Analysis Project; DMD = Duchenne muscular dystrophy; DNHS = Duchenne Natural History Study; NHD = natural history data; RWD = realworld data; $6 \mathrm{MWD}=6$-minute walk distance.

Enrollment challenges for clinical trials of Duchenne muscular dystrophy (DMD) have intensified the need to make informative use of real-world data (RWD) and natural history data (NHD) in drug evaluations. The enrollment challenges stem from the rarity of DMD itself, the further rarity of certain treatment-amenable genetic subtypes, and the practical and ethical implications of placebo arms for a progressive, life-limiting disease with few treatment options. Compounding these enrollment challenges, variability in primary outcomes such as the 6-minute walk distance $(6 \mathrm{MWD})^{1}$ makes it difficult to detect, or exclude, clinically important treatment effects with readily achievable sample sizes. In this setting, using RWD/NHD to contextualize, augment, or potentially replace placebo arms could significantly accelerate the development of effective therapies for DMD.

However, use of RWD/NHD controls for patients enrolled in clinical trials raises well-founded concerns. It is reasonable to ask whether differences between these settings might produce a disqualifying bias in patient outcomes; indeed, the potential for such bias has been observed in other neuromuscular diseases $^{2}$ and noted by regulators. ${ }^{3}$ Particular points of concern in $\mathrm{DMD}$ are potential differences in patient characteristics, background therapies, ${ }^{4,5}$ and levels of motivation ${ }^{6,7}$ and fatigue, the last being especially relevant for performance-based outcomes such as 6MWD.

The suitability of RWD/NHD controls in DMD depends on the magnitude of these potential biases. To assess this bias empirically, we conducted a multi-institution, multi-registry study comparing 48-week changes in 6MWD between DMD clinical trial placebo arms and RWD/NHD, accounting for inclusion criteria and baseline prognostic factors.

\section{Methods}

\section{Data sources}

Data were obtained from 6 clinical trial placebo arms and 5 RWD or NHD sources. RWD for this study were contributed by Universitaire Ziekenhuizen Leuven. Participating collaborators contributing NHD included the DMD Italian Group, the CINRG Duchenne Natural History Study (DNHS), ImagingDMD, and the PRO-DMD-01 prospective natural history study, from which data were provided to the Collaborative Trajectory Analysis Project (cTAP) by CureDuchenne, a DMD patient foundation.

\section{Clinical trial placebo arms}

Clinical trials in DMD were identified via reviews of PubMed, clinicaltrials.gov, and briefing documents posted by the Food and Drug Administration. Placebo arms were included if they reported change from baseline in 6MWD at 48 weeks in patients with DMD. The following trials were identified as eligible, and their placebo arms were included in the present study: tadalafil DMD phase 3 trial $(\mathrm{NCT} 01865084)^{8}$; ataluren phase 2b $(\mathrm{NCT} 00592553)^{9}$; ataluren phase $3(\mathrm{NCT} 01826487)^{10}$; drisapersen phase 2 (pooled data across 2 phase 2 trials [NCT01153932 and NCT01462292]), and drisapersen phase 3 (NCT01254019). ${ }^{11}$ Published results from the 6 identified clinical trial placebo arms were extracted in duplicate by 2 reviewers working independently.

These 6 clinical trial placebo arms encompassed 4 distinct sets of key inclusion criteria that differed with respect to baseline age and functional status (table 1 ). The ataluren phase $2 \mathrm{~b}$ trial did not require enrolled patients to be on steroids, but all other trials required patients to have used steroids for at least 6 months and to have been on a stable corticosteroid regimen for at least 3 months before trial entry. All trials were 48 weeks in duration. Results from the 2 phase 2 trials of drisapersen were combined for analyses due to equivalent inclusion/exclusion criteria and the relatively small number of patients in each trial.

\section{RWD and NHD sources}

RWD/NHD were drawn from the following sources, which collectively represent $>50$ care centers. Key characteristics of each data source are summarized in table 2 .

\section{Universitaire Ziekenhuizen Leuven (Leuven)}

Data were collected from boys with DMD who were monitored in routine clinical practice at the Universitaire Ziekenhuizen pediatric neurology clinic in Leuven, Belgium. Clinic visits occurred approximately every 6 months.

\section{DMD Italian Group}

The DMD Italian Group is a registry of 13 tertiary neuromuscular clinical centers in Italy. Data were collected from routine clinical practice and curated at 12 -month intervals.

\section{The CINRG DNHS}

CINRG is a clinical trial network comprising $>20$ worldwide clinical study sites. ${ }^{12}$ The specific data used in this study were from the CINRG DNHS (NCT00468832), ${ }^{13,14}$ a prospective longitudinal study of a cohort of patients with DMD. ${ }^{13}$ For ambulatory patients, assessments were conducted every 3 months for the first year of follow-up, every 6 months in the second year of follow-up, and annually thereafter.

\section{ImagingDMD}

ImagingDMD (NCT01484678) ${ }^{15}$ is a longitudinal, multicenter, observational study of boys with DMD and agematched controls without DMD. Only data from boys with 
Table 1 Key inclusion/exclusion criteria ${ }^{a}$ for trials

\begin{tabular}{|c|c|c|c|c|c|}
\hline \multirow[b]{2}{*}{ Trial } & \multirow{2}{*}{$\begin{array}{l}\text { No. of patients in trial } \\
\text { placebo arms }\end{array}$} & \multicolumn{4}{|c|}{ Key inclusion/exclusion criteria } \\
\hline & & Steroid use, mo & Age, y & 6MWD, m & Rise from supine, $s$ \\
\hline Tadalafil phase 3 & 116 & $\geq 6$ & $7-14$ & $200-400$ & - \\
\hline Ataluren phase $\mathbf{2 b}$ & 57 & $-{ }^{\mathrm{b}}$ & $\geq 5$ & $\geq 75$ & - \\
\hline Ataluren phase 3 & 115 & $\geq 6$ & $7-16$ & $\geq 150$ & - \\
\hline Drisapersen phase $2^{c}$ & 34 & $\geq 6$ & $\geq 5$ & $\geq 75$ & $\leq 7$ \\
\hline Drisapersen phase 3 & 61 & $\geq 6$ & $\geq 5$ & $\geq 75$ & - \\
\hline
\end{tabular}

Abbreviation: 6MWD = 6-minute walk distance.

a Identified via systematic review of PubMed, clinicaltrials.gov, and briefing documents from the Food and Drug Administration; baseline characteristics and 48-week changes in 6MWD extracted by 2 reviewers working independently.

${ }^{b}$ The ataluren phase $2 b$ trial included both steroid-treated and steroid-naive patients. Of the 57 patients in the placebo arm, 40 had $\geq 6$ months of steroid use at baseline.

c Pooled 2 phase 2 trials.

DMD were included in this study. Study participants were recruited from across the United States and received assessments at 1 of 3 sites (University of Florida, Oregon Health \& Science University/Shriners Hospital Portland, and the Children's Hospital of Philadelphia). Data were collected every 12 months and every 3 or 6 months in the first year in a subset of patients.

\section{PRO-DMD-01}

The PRO-DMD-01 study (NCT01753804) was a prospective observational study of disease progression in boys with DMD sponsored by BioMarin Pharmaceutical. Data were provided by CureDuchenne, a 501(3)c DMD patient foundation. The study included patients from 16 centers in the United States, Argentina, Belgium, Brazil, France, Germany, Italy, the Netherlands, Sweden, and Turkey. Study assessments occurred every 6 months.

\section{Standard protocol approvals, registrations, and patient consents}

RWD/NHD sources were approved by ethics committees from each institution (the University Hospitals Leuven [Leuven], Catholic University, Rome [DMD Italian Group], each participating center for The Cooperative International Neuromuscular Research Group [CINRG] and PRO-DMD01, the University of Florida, Children's Hospital of Philadelphia, and Oregon Health and Science University [Imaging DMD]). Written informed consent/assent was obtained from each participant or caregiver as appropriate before the study procedures were conducted.

\section{Outcome assessments}

This study focused on 48-week change in 6MWD ( $\triangle 6 \mathrm{MWD})$, which served as the primary outcome in each of the included clinical trials. All assessments of 6MWD in the placebo arms and RWD/NHD sources were based on modified American Thoracic Society criteria ${ }^{1}$ and administered by trained assessors or clinical experts. Training procedures are described for each data source in table 2. Participants who were unable to complete the 6-minute walk test at the time of their assessment were assigned a $6 \mathrm{MWD}$ of 0 meters.

\section{Sample selection in RWD/NHD sources}

Separate samples of RWD/NHD were drawn for each set of clinical trial inclusion/exclusion criteria. To be included in the analysis, an interval of follow-up from RWD/NHD was required to meet each of the following criteria: (1) at the first clinic visit in the interval (referred to as the baseline visit), the patient met the age, steroid duration, and functional criteria specified in the inclusion/exclusion criteria of the comparator trial as detailed in table 1 ; (2) the baseline visit and a subsequent follow-up visit were separated by $\sim 48$ weeks (9-13 months, inclusive); and (3) $6 \mathrm{MWD}$ was assessed at the baseline and endpoint visits (figure 1). If a patient had multiple intervals meeting these criteria, all nonoverlapping intervals were included in the analyses. The endpoint visit for 1 interval was allowed to serve as the baseline visit for the subsequent interval, but further overlap was disallowed.

\section{Statistical analysis}

For RWD/NHD sources, observed changes in 6MWD over the 9- to 13-month period were rescaled to reflect 48-week changes in 6MWD. If a patient lost ambulation before his endpoint visit or if a linear rescaling of his change in $6 \mathrm{MWD}$ resulted in a projected $6 \mathrm{MWD}$ at 48 weeks of $<0$ meters, the patient was assumed to have lost the ability to complete the $6 \mathrm{MWD}$ assessment by week 48 , and their $\triangle 6 \mathrm{MWD}$ was the negative of their baseline 6MWD.

In each RWD/NHD source, means and standard errors of $\triangle 6 \mathrm{MWD}$ were estimated from all eligible patient intervals. When estimating standard errors for statistical comparisons, we used generalized estimating equations with an exchangeable covariance structure to account for use of multiple intervals from individual patients. ${ }^{16}$ Pairwise differences in mean $\triangle 6 \mathrm{MWD}$ among RWD/NHD cohorts subjected to the same inclusion/exclusion criteria were also assessed. Control of the false discovery rate ${ }^{17}$ was used to assess statistical significance across multiple comparisons. 
Table 2 Characteristics of included RWD/NHD sources

\begin{tabular}{|c|c|c|c|c|c|}
\hline & $\begin{array}{l}\text { DMD Italian } \\
\text { Group }\end{array}$ & UZ Leuven & CINRG DNHS & ImagingDMD & PRO-DMD-01 \\
\hline Locations & 13 centers in Italy & $\begin{array}{l}1 \text { center in } \\
\text { Belgium }\end{array}$ & $\begin{array}{l}20 \text { centers across US, } \\
\text { Canada, Argentina, Sweden, } \\
\text { Italy, Israel, India, and } \\
\text { Australia }\end{array}$ & $\begin{array}{l}\text { University of Florida, } \\
\text { Children's Hospital of } \\
\text { Philadelphia, Oregon Health } \\
\text { \& Science University/ } \\
\text { Shriners Hospital Portland }\end{array}$ & $\begin{array}{l}16 \text { sites across US, South } \\
\text { America, and Europe }\end{array}$ \\
\hline $\begin{array}{l}\text { Data } \\
\text { collection } \\
\text { time period }\end{array}$ & 2008-2013 & 2007-present & $\begin{array}{l}\text { Overall: 2006-2016 } \\
\text { 6MWD: 2012-2016 }\end{array}$ & 2010-2016 & 2012-2016 \\
\hline $\begin{array}{l}\text { Inclusion and } \\
\text { exclusion } \\
\text { criteria }\end{array}$ & $\begin{array}{l}\text { Genetically } \\
\text { proven DMD } \\
\text { diagnosis } \\
\text { Age } \geq 5 \mathrm{y} \\
\text { Walks } \\
\text { independently } \\
\geq 75 \mathrm{~m} \\
\text { No moderate or } \\
\text { severe learning } \\
\text { difficulties or } \\
\text { behavioral } \\
\text { problems } \\
3 \text { y of annual }(12 \pm \\
3 \text { months) } 6 \mathrm{MWD} \\
\text { assessments } \\
\text { performed at the } \\
\text { same center }\end{array}$ & $\begin{array}{l}\text { Genetically } \\
\text { proven DMD } \\
\text { Age } 4.5-17.5 \text { y } \\
\text { No severe } \\
\text { cognitive or } \\
\text { behavioral } \\
\text { disorder } \\
\text { impairing } \\
\text { compliance }^{\text {a }}\end{array}$ & $\begin{array}{l}\text { Genetically proven DMD or } \\
\text { clinical diagnosis with an } \\
\text { older male sibling with } \\
\text { genetically proven DMD (for } \\
\text { enrollees } 2-5 \text { y of age) } \\
\text { Indication of dystrophin } \\
\text { mutation from DNA analysis, } \\
\text { muscle biopsy, creatinine } \\
\text { kinase level (for enrollees } \geq 5 \\
\text { y of age) } \\
\text { Excluded at enrollment if } \\
\text { walking unassisted beyond } \\
\text { age } 13 \text { y (glucocorticoid } \\
\text { naive) or } 16 \text { y (on } \\
\text { glucocorticoids) }\end{array}$ & $\begin{array}{l}\text { Ambulatory and } \\
\text { nonambulatory boys } \\
\text { between } 5 \text { and } 18 \text { y of age } \\
\text { Diagnosed with DMD } \\
\text { Onset of symptoms before } \\
\text { age } 5 \text { y } \\
\text { No contraindication to an } \\
\text { MRI examination } \\
\text { No unstable medical } \\
\text { problems } \\
\text { Must be able to cooperate } \\
\text { during testing and not have } \\
\text { cognitive deficits } \\
\text { No secondary conditions } \\
\text { that may affect muscle } \\
\text { metabolism, muscle } \\
\text { function, or functional ability }\end{array}$ & $\begin{array}{l}\text { Genetically proven DMD } \\
\text { Age } 3-18 \text { y } \\
\text { Willing and able to comply } \\
\text { with protocol requirements } \\
\text { Life expectancy of at least } 3 y \\
\text { Able to give informed assent } \\
\text { and/or consent in writing } \\
\text { signed by the participant } \\
\text { and/or parent(s)/legal } \\
\text { guardian }\end{array}$ \\
\hline $\begin{array}{l}\text { Typical } \\
\text { standard of } \\
\text { care, including } \\
\text { glucocorticoid } \\
\text { use and } \\
\text { physical } \\
\text { therapy }\end{array}$ & $\begin{array}{l}\text { 92/96 patients on } \\
\text { glucocorticoids, } \\
\sim 80 \% \text { on } \\
\text { deflazacort; } 42 \\
\text { on daily and } 50 \\
\text { on intermittent } \\
\text { regimens }\end{array}$ & $\begin{array}{l}\text { Glucocorticoids } \\
\text { usually } \\
\text { prescribed from } \\
\text { age of } 4-6 \text { y on; } \\
90 \% \text { received } 0.90 \\
\text { mg/kg daily } \\
\text { deflazacort } \\
\text { Physical therapy } \\
\text { advice for } \\
\text { prevention of } \\
\text { contractures }\end{array}$ & $\begin{array}{l}\text { Majority of patients are prior } \\
\text { or current glucocorticoid } \\
\text { users: among initial } \\
\text { enrollees, } 62 \% \text { on } \\
\text { glucocorticoid therapy, } 14 \% \\
\text { had prior glucocorticoid use, } \\
24 \% \text { glucocorticoid naive } \\
\text { Known differences in } \\
\text { standard of care for both } \\
\text { glucocorticoids and physical } \\
\text { therapy across sites; not all } \\
\text { participants receive care at } \\
\text { the CINRG sites }\end{array}$ & $\begin{array}{l}\text { Majority of patients are } \\
\text { current glucocorticoid users: } \\
74 \% \text { of enrollees received } \\
\text { steroids at study entry; } 87 \% \\
\text { received steroids at any time } \\
\text { during course of study } \\
\text { Most participants do not } \\
\text { receive care at the } \\
\text { ImagingDMD sites } \\
\text { Differences in standard of } \\
\text { care are expected both for } \\
\text { glucocorticoids and physical } \\
\text { therapy }\end{array}$ & $\begin{array}{l}\text { At baseline } 208 \text { participants } \\
\text { ( } 78 \%) \text { were using steroids } \\
\text { for DMD, mainly in a } \\
\text { continuous }(56.2 \%) \text { or } \\
\text { intermittent }(15.4 \%) \\
\text { regimen, and } 59(22.1 \%) \\
\text { used none (mostly younger } \\
\text { boys) }\end{array}$ \\
\hline $\begin{array}{l}\text { No. of patients } \\
\text { in database }\end{array}$ & 96 & 150 & 440 & 106 & 269 \\
\hline $\begin{array}{l}\text { No. of patients } \\
\text { with } \geq 16 \mathrm{MWD} \\
\text { assessment }\end{array}$ & 96 & 103 & 149 & 102 & 219 \\
\hline $\begin{array}{l}\text { 6MWD } \\
\text { assessment } \\
\text { details }\end{array}$ & $\begin{array}{l}\text { Modified ATS } \\
\text { Trained assessors } \\
\text { at each center } \\
6 \mathrm{MWD} \text { done every } \\
\sim 12 \text { mo } \\
\text { Inability to } \\
\text { complete } 6 \mathrm{MWD} \\
\text { due to loss of } \\
\text { ambulation } \\
\text { recorded as } \\
6 \mathrm{MWD}=0 \\
\text { No missing data } \\
\text { on 6MWD }\end{array}$ & $\begin{array}{l}\text { Modified ATS } \\
\text { Same } 2 \text { trained } \\
\text { and experienced } \\
\text { physiotherapists } \\
6 \mathrm{MWD} \text { done } \\
\text { every } 6 \text { mo } \\
\text { Inability to } \\
\text { complete } 6 \mathrm{MWD} \\
\text { due to loss of } \\
\text { ambulation } \\
\text { recorded as } \\
6 \mathrm{MWD}=0 \\
\text { Minimal missing } \\
\text { data on } 6 \mathrm{MWD} \\
\text { because it is part } \\
\text { of the standard } \\
\text { assessment }\end{array}$ & $\begin{array}{l}\text { Modified ATS } \\
\text { Clinical evaluators at each } \\
\text { site participate in annual } \\
\text { central training and } \\
\text { reliability testing; } 2 \text { full-time } \\
\text { expert clinical evaluators } \\
\text { train new clinical evaluators } \\
6 \mathrm{MWD} \text { done at least } \\
\text { annually (more frequent in } \\
\text { first } 2 \text { y) } \\
\text { Inability to complete } 6 \mathrm{MWD} \\
\text { due to loss of ambulation } \\
\text { recorded as } 6 \mathrm{MWD}=0 \\
6 \mathrm{MWD} \text { is attempted in all } \\
\text { participants who can be } \\
\text { expected to walk at least } \\
75 \text { m; a patient who is unable } \\
\text { to ambulate } 10 \text { m on a } 10-\mathrm{m} \\
\text { walk/run test is given } 6 \mathrm{MWD} \\
=0\end{array}$ & $\begin{array}{l}\text { Modified ATS } \\
\text { Evaluators at each site were } \\
\text { trained and certified } \\
\text { Inability to complete } 6 \mathrm{MWT} \\
\text { due to loss of ambulation } \\
\text { recorded as } 6 \mathrm{MWD}=0 \\
6 \mathrm{MWT} \text { performed annually } \\
\text { (more frequently for a } \\
\text { subset in the first year) }\end{array}$ & $\begin{array}{l}\text { Modified ATS } \\
\text { Testing guidelines provided } \\
\text { to each center in operations } \\
\text { manual } \\
\text { Two evaluators for each test } \\
6 \mathrm{MWD} \text { done every } 6 \text { mo } \\
\text { Inability to complete } 6 \mathrm{MWD} \\
\text { due to loss of ambulation } \\
\text { recorded as } 6 \mathrm{MWD}=0\end{array}$ \\
\hline
\end{tabular}

Abbreviations: ATS = American Thoracic Society; CINRG DNHS = The Cooperative International Neuromuscular Research Group Duchenne Natural History Study; DMD = Duchenne muscular dystrophy; FOR-DMD = Finding the Optimum Regimen for Duchenne Muscular Dystrophy; RWD/NHD; real-world data/ natural history data; $6 \mathrm{MWD}=6$-minute walk distance; 6MWT = 6-minute walk test; UZ = Universitaire Ziekenhuizen

a Patients on trials are flagged and were excluded from the present analyses. Some patients are participating in DMD-PRO-01 but do not differ in care or studied assessments.

${ }^{\mathrm{b}} \mathrm{A}$ few patients participated in exon skipping trials $(\sim 3)$ or FOR-DMD $(\sim 2)$; FOR-DMD patients are included and assumed to be on steroids. 
Figure 1 Study design diagram

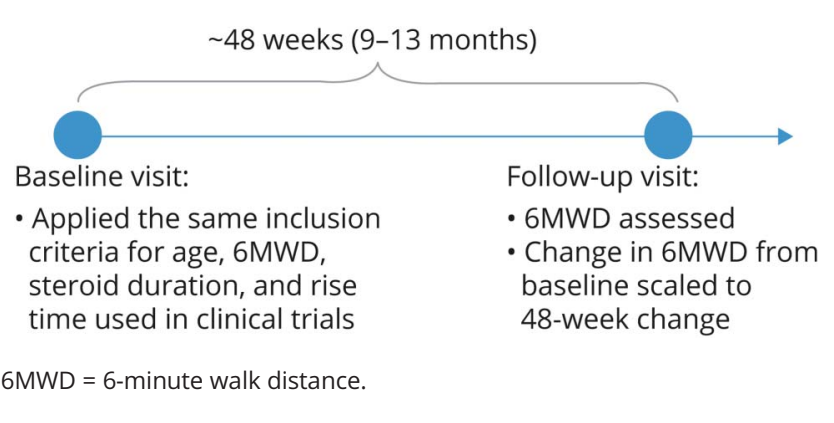

\section{Sensitivity analyses}

Two sets of sensitivity analyses were conducted. First, to assess whether differences in distribution of steroid type at baseline influenced the results, $\triangle 6 \mathrm{MWD}$ was compared within the subgroup of patients receiving deflazacort, which was the most commonly used steroid $(68 \%-84 \%)$ in the RWD/NHD sources with such information available. Second, to assess the sensitivity of the results to the time frame used to approximate 48-week follow-up periods in RWD/NHD sources, the analysis was repeated using observed changes that were 10 to 12 months apart, instead of 9 to 13 months as used in the primary analyses.

\section{Covariate adjustment}

Additional analyses comparing $\triangle 6 \mathrm{MWD}$ between placebo arms and RWD/NHD after baseline covariate adjustment were conducted using data sources for which patient-level data, with measurement of $6 \mathrm{MWD}$ and the prognostic factors listed below, were currently available within cTAP. These included the placebo arms from 3 trials (tadalafil DMD phase 3 , ataluren phase $2 b$, ataluren phase 3 ) and from 3 RWD/ NHD sources (Leuven, ImagingDMD, PRO-DMD-01). Similar to the analyses of RWD/NHD sources described above, these analyses were based on all nonoverlapping intervals of $\sim 48$-week changes. To be included in these analyses, patients were required to have $6 \mathrm{MWD} \geq 75 \mathrm{~m}$ at the baseline visit of the interval and 6MWD available at both the baseline and follow-up visits. Multivariable regression models, with generalized estimating equations to account for the use of multiple follow-up intervals from some patients, were used to compare changes in 6MWD between trial placebo and RWD/NHD after adjustment for age and known prognostic factors: steroid duration, baseline 6MWD, steroid type, ability to perform rise from supine, and completion times for timed function tests (rise from supine, 4-stair climb, and 10 meter walk/run), ${ }^{13}$ as well as height, weight, and body mass index. ${ }^{18}$

\section{Data availability}

All relevant data are reported within the article. Data requests may be directed to the individual institutions and clinical networks that have collected and curated patient data. These organizations (Universitaire Ziekenhuizen, the DMD Italian Group, CINRG, Imaging DMD, and CureDuchenne) will consider data requests according to their own data-sharing policies and governance.

\section{Results}

\section{Patient characteristics}

The analyses included $\mathrm{n}=383$ patients on placebo arms, each contributing one $\sim 48$-week follow-up interval, and $n=430$ patients contributing a total of $919 \sim 48$-week follow-up intervals from RWD/NHD sources. The numbers of patients and intervals analyzed varied according to the specific inclusion/exclusion criteria applied to each source (table 3).

After harmonization of inclusion/exclusion criteria, the mean age was generally older for participants in RWD/NHD sources compared to placebo arms by 1 to 2 years, except for CINRG DNHS, in which boys were closer to 3 years older on average for most comparisons (table 3 ). In nearly all of the comparisons between trial placebo arms and harmonized RWD/NHD cohorts, baseline $6 \mathrm{MWD}$ was within $\pm 30 \mathrm{~m}$; the largest difference was $74 \mathrm{~m}$ for placebo. Data on type of steroid used at baseline were not always available for comparison between trials and RWD/NHD sources. However, for comparisons for which steroid type was available, deflazacort was more commonly used in these RWD/NHD sources than in the corresponding trials.

\section{Comparison of 48-week changes in 6MWD}

Differences in mean $\triangle 6 \mathrm{MWD}$ between trial placebo arms and harmonized RWD/NHD cohorts ranged from $-19.4 \mathrm{~m}$ (indicating smaller declines in RWD/NHD than in placebo) to $19.5 \mathrm{~m}$ (indicating larger declines in RWD/NHD than in placebo) (figure 2). Mean $\triangle 6 \mathrm{MWD}$ in RWD/NHD cohorts was numerically smaller in magnitude of decline (indicating better preservation of function) than placebo in 17 comparisons and larger than placebo in 7 comparisons. None of the differences observed between trial placebo arms and RWD/ NHD cohorts were statistically significant (table 4).

Among the harmonized RWD/NHD cohorts, means for $\Delta 6 \mathrm{MWD}$ were all within $25 \mathrm{~m}$ of each other; only 1 of the 46 pairwise comparisons of RWD/NHD cohorts reached a nominal $p<0.05$. This was not statistically significant at the $5 \%$ level after adjustment for multiple comparisons.

\section{Sensitivity analyses}

Analyses among deflazacort users at baseline were possible for comparisons of RWD/NHD against placebo arms from the tadalafil DMD phase 3 and ataluren phase 3 trials; these were the only 2 trials that reported outcomes in deflazacort-treated subpopulations. Analyses were done only among deflazacort users because deflazacort was the corticosteroid predominantly used in the RWD/NHD sources analyzed here. As in the primary analyses, mean $\triangle 6 \mathrm{MWD}$ was similar between the trial placebo arms and RWD/NHD sources in this subgroup (table 5). Separately, sensitivity analyses based on 
Table 3 Patient characteristics in trial placebo arms and RWD/NHD sources subjected to the inclusion/exclusion criteria of the trial

\begin{tabular}{|c|c|c|c|c|c|c|}
\hline & $\begin{array}{l}\text { Trial } \\
\text { placebo arm }\end{array}$ & Leuven & $\begin{array}{l}\text { DMD Italian } \\
\text { Group }\end{array}$ & CINRG DNHS & ImagingDMD & PRO-DMD-01 \\
\hline \multicolumn{7}{|l|}{ Tadalafil phase 3} \\
\hline Intervals, patients, $\mathrm{n}$ & 116,116 & 68,33 & 124,60 & 27,22 & 91,48 & 121,90 \\
\hline Age, $^{a} y$ & $9.4 \pm 1.8$ & $10.4 \pm 1.7$ & $9.9 \pm 1.7$ & $12.3 \pm 2.4$ & $10.0 \pm 1.8$ & $10.0 \pm 1.8$ \\
\hline $6 M W D,{ }^{a} \mathrm{~m}$ & $338.0 \pm 51.0$ & $323.0 \pm 57.9$ & $323.2 \pm 51.7$ & $264.4 \pm 123.7$ & $326.4 \pm 50.9$ & $318.6 \pm 57.4$ \\
\hline Deflazacort, n (\%) & $58(50.0)$ & 55 (80.9) & - & $18(66.7)$ & $64(70.3)$ & $75(62.0)$ \\
\hline \multicolumn{7}{|l|}{ Ataluren phase $\mathbf{2 b}$} \\
\hline Intervals, patients, $\mathrm{n}$ & 57,57 & 110,47 & 261,92 & 86,60 & 179,69 & 283,162 \\
\hline Age, $^{a} y$ & $8.3 \pm 2.3$ & $10.0 \pm 2.3$ & $9.2 \pm 2.1$ & $11.0 \pm 3.5$ & $9.8 \pm 2.4$ & $9.6 \pm 2.6$ \\
\hline $6 M W D,{ }^{a} \mathrm{~m}$ & $361.1 \pm 87.5$ & $351.1 \pm 88.5$ & $375.8 \pm 93.8$ & $322.4 \pm 169.4$ & $368.9 \pm 81.3$ & $362.3 \pm 95.1$ \\
\hline Deflazacort, n (\%) & - & $91(82.7)$ & - & $54(62.8)$ & $129(73.3)$ & $191(67.5)$ \\
\hline \multicolumn{7}{|l|}{ Ataluren phase 3} \\
\hline Intervals, patients, $\mathrm{n}$ & 115,115 & 94,39 & 222,90 & 59,40 & 150,65 & 233,146 \\
\hline $\mathrm{Age}^{a} \mathrm{y}$ & $9.0 \pm 1.7$ & $10.3 \pm 1.8$ & $9.5 \pm 1.7$ & $12.0 \pm 2.5$ & $10.2 \pm 2.0$ & $10.0 \pm 2.1$ \\
\hline 6MWD, ${ }^{a} \mathrm{~m}$ & $362.7 \pm 81.4$ & $347.6 \pm 87.9$ & $381.5 \pm 89.3$ & $309.8 \pm 165.8$ & $372.3 \pm 77.0$ & $365.3 \pm 92.1$ \\
\hline Deflazacort, n (\%) & $54(47.0)$ & $79(84.0)$ & - & $41(69.5)$ & $107(72.3)$ & $158(67.8)$ \\
\hline \multicolumn{7}{|l|}{ Drisapersen phase 2} \\
\hline Intervals, patients, $\mathrm{n}$ & 34,34 & 66,32 & - & 46,34 & 126,52 & 175,104 \\
\hline Age, $^{a} y$ & $7.4 \pm 1.6$ & $9.2 \pm 2.3$ & - & $9.3 \pm 2.9$ & $9.3 \pm 2.4$ & $8.6 \pm 2.0$ \\
\hline $6 M W D,{ }^{a} \mathrm{~m}$ & $409.4 \pm 50.7$ & $393.6 \pm 65.2$ & - & $428.7 \pm 103.6$ & $397.4 \pm 65.2$ & $414.1 \pm 59.7$ \\
\hline Deflazacort, n (\%) & - & $57(86.4)$ & - & $24(52.2)$ & $91(74.0)$ & $124(70.9)$ \\
\hline \multicolumn{7}{|l|}{ Drisapersen phase 3} \\
\hline Intervals, patients, $\mathrm{n}$ & 61,61 & 110,47 & 261,92 & 86,60 & 179,69 & 283,162 \\
\hline $\mathrm{Age}^{\mathrm{a}} \mathrm{y}$ & $8.0 \pm 2.4$ & $10.0 \pm 2.3$ & $9.2 \pm 2.1$ & $11.0 \pm 3.5$ & $9.8 \pm 2.4$ & $9.6 \pm 2.6$ \\
\hline $6 M W D,{ }^{a} \mathrm{~m}$ & $348.0 \pm 92.2$ & $351.1 \pm 88.5$ & $375.8 \pm 93.8$ & $322.4 \pm 169.4$ & $368.9 \pm 81.3$ & $362.3 \pm 95.1$ \\
\hline Deflazacort, n (\%) & - & $91(82.7)$ & - & $54(62.8)$ & $129(73.3)$ & $191(67.5)$ \\
\hline
\end{tabular}

Abbreviations: CINRG DNHS = The Cooperative International Neuromuscular Research Group Duchenne Natural History Study; DMD = Duchenne muscular dystrophy; RWD/NHD = real-world data/natural history data; 6MWD = 6-minute walk distance.

a Summarized as mean \pm SD; Deflazacort use is summarized as number and $\%$ of intervals with deflazacort use at baseline.

follow-up visits spanning 10 to 12 months of follow-up in RWD/NHD data sources yielded results similar to those observed in the primary analyses: differences in mean $\triangle 6 \mathrm{MWD}$ between trial placebo arms and harmonized RWD/ NHD cohorts ranged from -18.3 to $20.4 \mathrm{~m}$, and none reached statistical significance (results not shown).

\section{Covariate adjustment}

Analyses with adjustment for baseline covariates were based on 822 intervals of follow-up among patients in placebo arms of the tadalafil phase 3 , ataluren phase $2 b$, and ataluren phase 3 trials (239 intervals from 239 patients) and from the Leuven, ImagingDMD, and PRO-DMD-01 RWD/NHD sources (583 intervals from 274 patients). In this sample, the difference in mean $\triangle 6 \mathrm{MWD}$ between placebo and RWD/NHD before adjustment was $-8.7 \mathrm{~m}(p=0.2)$, numerically indicating greater decline in placebo than in RWD/NHD. After adjustment for known baseline prognostic factors, the difference in mean $\Delta 6 \mathrm{MWD}$ was $7.7 \mathrm{~m}$ ( $95 \%$ confidence interval -3.8 to $19.3 ; p=0.2$ ).

\section{Discussion}

The findings of this study are supportive of the use of RWD/ NHD to contextualize, augment, or potentially replace placebo arms in DMD clinical trials and thus have important implications 
Figure 2 Forty-eight-week changes in 6MWD in trial placebo arms and harmonized real-world data/natural history data

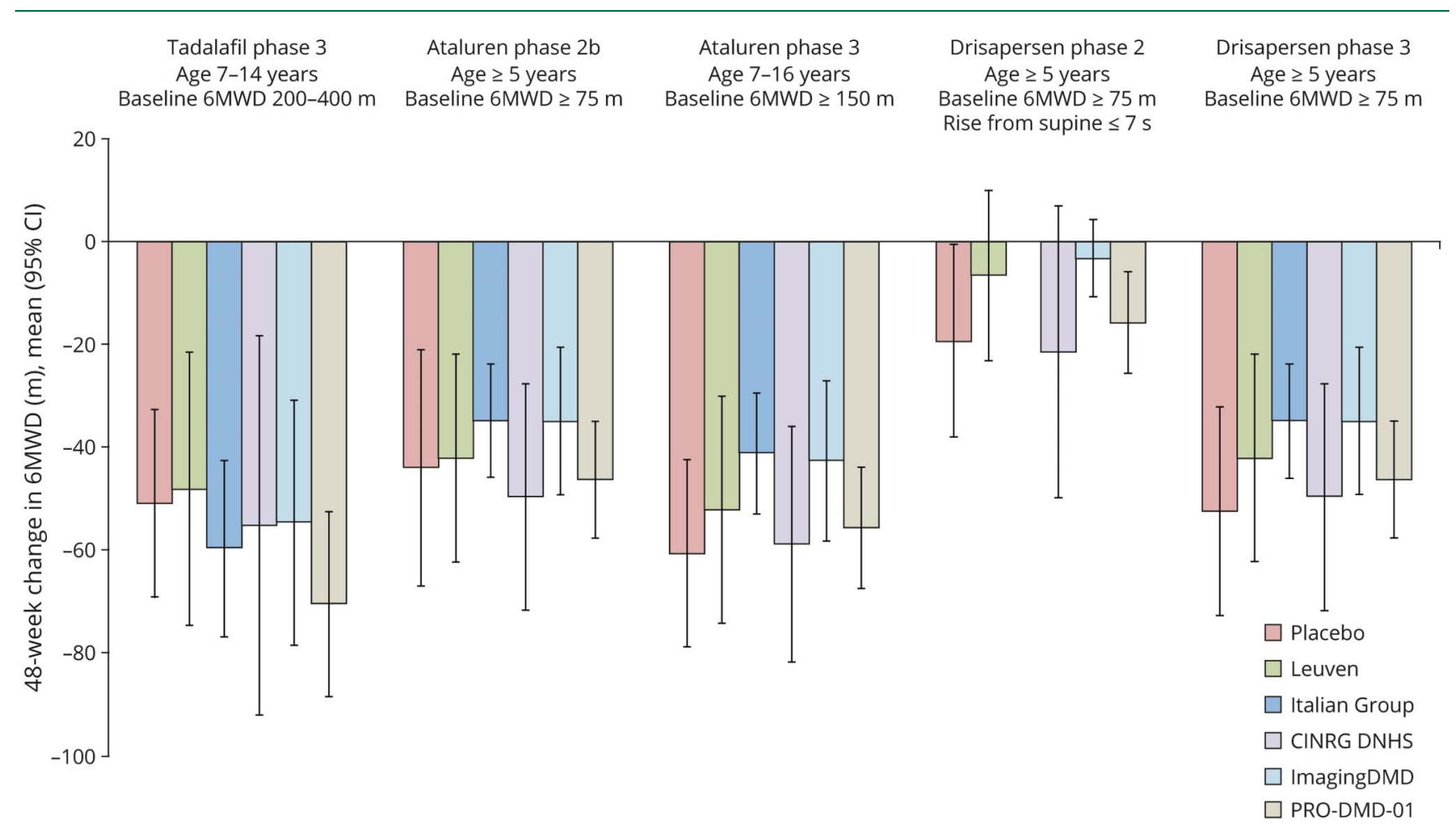

$\mathrm{Cl}$ = confidence interval; CINRG DNHS = The Cooperative International Neuromuscular Research Group Duchenne Natural History Study; DMD = Duchenne muscular dystrophy; 6MWD = 6-minute walk distance.

for drug evaluation in DMD. In particular, a fundamental motivation for this research was the concern that external controls might not be suitable for DMD because performance-based outcomes such as 6MWD could be biased by differences between clinical trial and RWD/NHD settings. ${ }^{2,3}$ We analyzed $>1,000$ patient-years of follow-up, encompassing data from all available clinical trial placebo arms and from 5 multinational, multiinstitutional RWD/NHD sources. We found that changes in
6MWD over 48 weeks were strikingly consistent between these settings when subjected to equivalent inclusion/exclusion criteria and after adjustment for multiple known prognostic factors. There was no evidence that changes in $6 \mathrm{MWD}$ were systematically milder in placebo arms compared to RWD/NHD. The 6MWD outcomes were also consistent among the different RWD/NHD sources analyzed. From these findings, we conclude that external controls can be suitable for drug evaluations in DMD.

Table 4 Forty-eight-week changes in 6MWD in trial placebo arms vs harmonized RWD/NHD

\begin{tabular}{|c|c|c|c|c|c|c|}
\hline \multirow[b]{2}{*}{ Placebo arm } & \multicolumn{6}{|c|}{ 48-wk change in 6MWD, mean $\pm S E, m$} \\
\hline & Placebo & Leuven & $\begin{array}{l}\text { DMD Italian } \\
\text { Group }\end{array}$ & CINRG DNHS & ImagingDMD & PRO-DMD-01 \\
\hline Tadalafil phase 3 & $-51.0 \pm 9.3$ & $\begin{array}{l}-48.3 \pm 13.6 \\
p=0.87\end{array}$ & $\begin{array}{l}-59.8 \pm 8.8 \\
p=0.49\end{array}$ & $\begin{array}{l}-55.2 \pm 18.8 \\
p=0.84\end{array}$ & $\begin{array}{l}-54.7 \pm 12.2 \\
p=0.81\end{array}$ & $\begin{array}{l}-70.5 \pm 9.2 \\
p=0.14\end{array}$ \\
\hline Ataluren phase $\mathbf{2 b}$ & $-44.1 \pm 11.7$ & $\begin{array}{l}-42.2 \pm 10.3 \\
p=0.90\end{array}$ & $\begin{array}{l}-34.9 \pm 5.6 \\
p=0.48\end{array}$ & $\begin{array}{l}-49.7 \pm 11.2 \\
p=0.73\end{array}$ & $\begin{array}{l}-35.0 \pm 7.3 \\
p=0.51\end{array}$ & $\begin{array}{l}-46.4 \pm 5.8 \\
p=0.86\end{array}$ \\
\hline Ataluren phase 3 & $-60.7 \pm 9.3$ & $\begin{array}{l}-52.3 \pm 11.3 \\
p=0.57\end{array}$ & $\begin{array}{l}-41.3 \pm 6.0 \\
p=0.08\end{array}$ & $\begin{array}{l}-59.0 \pm 11.7 \\
p=0.91\end{array}$ & $\begin{array}{l}-42.7 \pm 7.9 \\
p=0.14\end{array}$ & $\begin{array}{l}-55.8 \pm 6.0 \\
p=0.21\end{array}$ \\
\hline Drisapersen phase 2 & $-19.3 \pm 9.6$ & $\begin{array}{l}-6.6 \pm 8.5 \\
p=0.33\end{array}$ & $N A^{a}$ & $\begin{array}{l}-21.5 \pm 14.5 \\
p=0.90\end{array}$ & $\begin{array}{l}-3.3 \pm 3.9 \\
p=0.13\end{array}$ & $\begin{array}{l}-15.8 \pm 5.0 \\
p=0.35\end{array}$ \\
\hline Drisapersen phase 3 & $-52.6 \pm 10.4$ & $\begin{array}{l}-42.2 \pm 10.3 \\
p=0.48\end{array}$ & $\begin{array}{l}-34.9 \pm 5.6 \\
p=0.14\end{array}$ & $\begin{array}{l}-49.7 \pm 11.2 \\
p=0.85\end{array}$ & $\begin{array}{l}-35.0 \pm 7.3 \\
p=0.17\end{array}$ & $\begin{array}{l}-46.4 \pm 5.8 \\
p=0.60\end{array}$ \\
\hline
\end{tabular}

Abbreviations: CINRG DNHS = The Cooperative International Neuromuscular Research Group Duchenne Natural History Study; DMD = Duchenne muscular dystrophy; NA = not available; RWD/NHD = real-world data/natural history data; SE = standard error; 6MWD = 6-minute walk distance.

a Results not available due to absence of rise from supine data, which was necessary to apply the trial inclusion criteria. 
Table 5 Sensitivity analysis among deflazacort users: 48-week changes in 6MWD in trial placebo arms vs harmonized RWD/NHD

\begin{tabular}{|c|c|c|c|c|c|}
\hline \multirow[b]{2}{*}{ Placebo arm } & \multicolumn{5}{|c|}{ 48-wk change in 6MWD, mean $\pm S E, m$} \\
\hline & Placebo & Leuven & CINRG DNHS & ImagingDMD & PRO-DMD-01 \\
\hline Tadalafil phase 3 & $-34.2 \pm 13.0$ & $\begin{array}{l}-42.8 \pm 16.0 \\
p=0.68\end{array}$ & $\begin{array}{l}-49.8 \pm 25.9 \\
p=0.59\end{array}$ & $\begin{array}{l}-35.7 \pm 12.0 \\
p=0.93\end{array}$ & $\begin{array}{l}-59.5 \pm 10.5 \\
p=0.13\end{array}$ \\
\hline Ataluren phase 3 & $-39.0 \pm 15.1$ & $\begin{array}{l}-46.7 \pm 12.6 \\
p=0.70\end{array}$ & $\begin{array}{l}-60.0 \pm 14.9 \\
p=0.32\end{array}$ & $\begin{array}{l}-29.8 \pm 7.4 \\
p=0.59\end{array}$ & $\begin{array}{l}-47.3 \pm 6.0 \\
p=0.61\end{array}$ \\
\hline
\end{tabular}

Abbreviations: CINRG DNHS = The Cooperative International Neuromuscular Research Group Duchenne Natural History Study; DMD = Duchenne muscular dystrophy; RWD/NHD = real-world data/natural history data; $\mathrm{SE}=$ standard error; $6 \mathrm{MWD}$ = 6-minute walk distance.

The notable consistency we observed in 6MWD outcomes occurred despite a number of important differences across the studied data sources. Patients in the placebo arms and their caregivers and providers were blinded to receipt of placebo but were also aware of the patient's enrollment in an interventional trial and the possibility of receiving active therapy, a possibility that was absent in the RWD/NHD. With this awareness, patients in the placebo arms may have experienced different levels of hope for improvement or motivation during functional tests or received different cues, even unintentionally, from family members or from the health care professionals administering the $6 \mathrm{MWD}$ tests compared to those in RWD/NHD. In addition, boys enrolled in placebo arms were younger on average than those in the corresponding RWD/NHD cohorts. Because declines in 6MWD are progressive and tend to accelerate with age, this age difference would be expected to bias toward more favorable 6MWD outcomes in the placebo arms. Geography also varied, with different RWD/NHD sources representing centers in North America, Europe, Oceania, and Asia; the multicenter clinical trials also represented diverse geographies. While some of the RWD/NHD data were drawn from centers providing care consistent with published recommendations ${ }^{19,20}$ (Leuven, DMD Italian Group, ImagingDMD), others captured data from a more globally diverse collection of study sites (PRO-DMD-01, CINRG) across which standards of care may have been more variable. In the absence of evidence to the contrary, these differences would have supported appropriate concerns about risk of bias in comparing effort-based outcomes such as the $6 \mathrm{MWD}$ across these settings and data sources. The findings of the present study mitigate such concerns and indicate that differences between clinical trial and RWD/NHD settings in DMD are unlikely to drive significant bias in external controls for 6MWD outcomes in DMD.

While these results are supportive of the use of external controls in DMD, we emphasize that any future application of external controls would need to be evaluated on a case-by-case basis. The results of the present study are most directly generalizable to comparisons of 48 -week change in $6 \mathrm{MWD}$, measured by trained assessors following modified American Thoracic Society criteria, between ambulatory, steroid-treated individuals in randomized placebo-controlled trials and the studied RWD/ NHD sources. It is especially important to note that all RWD/
NHD sources included in our study used consistent methodologies to assess $6 \mathrm{MWD}$ as previously reported. ${ }^{1}$ Physical therapists and investigators at these centers are often involved in concurrent clinical trials and are therefore trained with similar manuals and instructions. This highlights the importance of consistency of clinical assessments across care centers in DMD for maximizing the value of patient data for research and the development of therapies. Finally, it should be noted that comparisons between RWD/NHD and single-arm or uncontrolled studies would require an additional layer of caution; patients included in those studies are certain that they are receiving active therapy, whereas patients in the placebo arms included in the present study had only a probability of receiving blinded active therapy.

An important factor that could not be fully explored in this study was the use of steroids at different doses or administration frequencies. While all patients included in the analysis were receiving steroids, consistent with standard-of-care recommendations and clinical trial inclusion criteria, the particular steroid types, dosing regimens, and ages at initiation were not always available and are likely to have varied across time and across care centers. Sensitivity analyses conducted among patients receiving deflazacort, which was the most commonly used steroid in the RWD sources with such information available, and multivariable analyses adjusted for steroid type were consistent with the primary analyses and did not indicate any significant differences in $\triangle 6 \mathrm{MWD}$ between placebo and RWD/NHD.

Overall, the results of this study provide a strong foundation for use of RWD/NHD in DMD drug development and confirm the worthiness of additional research to extend these findings to additional clinical outcomes and to evaluate different study designs for using RWD/NHD in DMD. The overall promise of such research is further supported by the passage of the 21st Century Cures Act (2016) in the United States, which has spurred an increased need for understanding and evaluating appropriate uses of RWD in regulatory decision-making ${ }^{21,22}$ and an emerging framework for doing so. ${ }^{23,24}$ Representatives of the European Medicines Agency and the Organisation for Economic Co-operation and Development have also highlighted the importance of RWD/NHD for drug evaluation. ${ }^{25-27}$ 
Comparisons to external controls have proved important to drug approvals in several rare diseases, including neuronal ceroid lipofuscinoses type 2 (a form of Batten disease $)^{28}$ and Pompe disease. ${ }^{29}$ Against this background, the use of RWD/ $\mathrm{NHD}$ in DMD clinical trials is of particular interest because it could make efficient use of existing patient data, facilitate faster trial enrollment, and enable more patients to access active therapies as opposed to placebo.

A number of specific-use cases for RWD/NHD have merit in $\mathrm{DMD}$ drug development and are supported by the consistency in 6MWD outcomes observed in the present study. Placebo augmentation, for example, is being studied in $\mathrm{DMD}^{30}$ as a way to preserve much of the benefit of a randomized placebo arm while limiting the proportion of patients who receive placebo, e.g., to a $1: 3$ or $1: 4$ ratio with active therapy. In a placebo augmentation design, the randomized placebo arm data provide an internal, unbiased reference point that can be augmented with external NHD/RWD controls, provided that they exhibit reasonably consistent outcomes, to increase the statistical precision of the measured drug effect. Minimizing sample size requirements for placebo arms will be especially important, for example, in DMD trials targeting extremely rare subpopulations (e.g., ultrarare genotypes such as duplications in exon 2 , which occur in only $\sim 1 \%$ of all patients with $\mathrm{DMD}^{31}$ ), or when invasive assessments (e.g., muscle biopsies for monitoring the protein product of a gene therapy) present practical and ethical challenges for a blinded placebo arm. In some cases, no randomized placebo data will be available, and external RWD/ NHD will be the only source of potential comparative data. This often occurs in early-phase trials, in evaluations of longterm extension data after crossover of any patients receiving placebo to active therapy, or in phase 4 trials that are initiated after initial market authorization. While randomized placebo controls may not be feasible in these settings, longer-term comparative evidence based on suitable external controls may be required in regulatory evaluations after an accelerated or conditional approval, or for health economic evaluations.

Beyond the present study of 6MWD, similar assessments are needed for the consistency of additional outcomes important to DMD drug development, including the North Star Ambulatory Assessment, ${ }^{32,33}$ Performance of Upper Limb, ${ }^{34}$ and measures of pulmonary function. ${ }^{35}$ The performance of different statistical methods for using RWD/NHD in DMD drug evaluation also warrants evaluation, especially in terms of type I error control (i.e., avoiding false positives) while reducing sample size requirements. This includes different approaches to placebo augmentation, ${ }^{36-38}$ as well as approaches for making adjusted comparisons to fully external controls such as individual patient matching, propensity score-based methods, ${ }^{39}$ and multivariable regression. Evaluating the consistency of additional outcome measures, as provided for 6MWD in the present study, will establish the basis for the selection and justification of study designs and statistical approaches for incorporating RWD/NHD into DMD drug evaluations.
Our goal of understanding the consistency of 6MWD between RWD/NHD and placebo arm settings could be thoroughly addressed only by collaboratively analyzing a comprehensive collection of data sources. Accessing patient data and conducting consistent analyses across multiple registries and geographies can be challenging; collaborating through cTAP simplified and accelerated this process. The potential impact of this study to provide stronger context for drug evaluation and to potentially reduce the number of patients who need to be enrolled in placebo arms highlights the importance of data collection, data sharing, and collaboration for DMD drug development.

\section{Acknowledgment}

The authors are grateful to patients for participating in the clinical assessments and agreeing to make their data available for research. The authors thank Eli Lilly for contributing placebo arm data from the tadalafil DMD trial, as well as David A. Cox and John Landry of Eli Lilly for contributions to the conceptualization and interpretation of this research. Medical writing assistance was provided by Gloria DeWalt, an employee of Analysis Group, Inc. Ibrahima Dieye, Madeline Jenkins, and Intekhab Hossain, employees of Analysis Group, Inc, assisted with the development of this manuscript. Clinical assessments at UZ Leuven were curated by Marleen Van den Hauwe. The authors also thank members of the cTAP Joint Steering Committee, in particular Paolo Bettica, MD (Italfarmaco SpA), Michael Binks, MD (Pfizer Inc), Joanne Donovan, MD (Catabasis Pharmaceuticals), and Anne Heatherington, $\mathrm{PhD}$ (Summit Therapeutics plc), for their contributions to the conceptualization of the study, interpretation of the results, and review of the manuscript.

\section{Study funding}

This study was conducted within the cTAP, a precompetitive coalition of academic clinicians, drug developers, and patient foundations formed in 2015 to overcome the challenges of high variation in clinical trials in DMD. cTAP has received sponsorship from Astellas Pharma (Mitobridge), BioMarin Pharmaceutical, Bristol-Myers Squibb, Catabasis Pharmaceuticals, FibroGen, Inc, Italfarmaco SpA, Pfizer Inc, Marathon Pharmaceuticals, PTC Therapeutics, Sarepta Therapeutics, Shire plc, Solid Biosciences, Summit Therapeutics plc, Wave Life Sciences, Roche, Parent Project Muscular Dystrophy, Charley's Fund, and CureDuchenne, a founding patient advocacy partner and provider of initial seed funding to CTAP. Physical function testing at Universitaire Ziekenhuizen Leuven was funded by Fonds Spierzieke Kinderen. Collection of Italian Group NHD was funded by the Fondazione Telethon (GUP 09010 and GUP 07009). The CINRG DNHS was funded by the US Department of Education/National Institute on Disability and Rehabilitation Research (H133B031118, H133B090001); US Department of Defense (W81XWH-12-1-0417); NIH/National Institute of Arthritis and Musculoskeletal and Skin Diseases (R01AR061875); and Parent Project Muscular Dystrophy. The ImagingDMD study is supported by grant funding from the National Institute of Arthritis and Musculoskeletal and Skin 
Diseases and the National Institute of Neurologic Disorders and Stroke of the NIH (Magnetic Resonance Imaging and Biomarkers in Muscular Dystrophy, R01AR056973). The PRODMD-01 study was sponsored by BioMarin Pharmaceutical.

\section{Disclosure}

N. Goemans has served on clinical steering committees and/ or as a consultant and received compensation from Eli Lilly, Italfarmaco SpA, PTC Therapeutics, BioMarin Pharmaceutical, Sarepta Therapeutics, Pfizer Inc, Roche, and Wave Life Sciences, and has served as site investigator for GlaxoSmithKline, Prosensa, BioMarin Pharmaceutical, Italfarmaco SpA, Sarepta Therapeutics, Wave Life Sciences, Roche, and Eli Lilly. J. Signorovitch is a member of the cTAP and is an employee of Analysis Group, Inc, a consulting firm that received funding to conduct this study. G. Sajeev and Z. Yao are employees of Analysis Group, Inc, a consulting firm that received funding to conduct this study. H. Gordish-Dressman is a paid consultant for AGADA BioSciences and co-owner and Board President of TRiNDS, LLC. C. McDonald has served as a consultant for PTC Therapeutics, BioMarin Pharmaceutical, Sarepta Therapeutics, Eli Lilly, Pfizer Inc, Santhera Pharmaceuticals, Cardero Therapeutics, Inc, Catabasis Pharmaceuticals, Capricor Therapeutics, Astellas Pharma (Mitobridge), and FibroGen, Inc; serves on external advisory boards related to DMD for PTC Therapeutics, Sarepta Therapeutics, Santhera Pharmaceuticals, and Capricor Therapeutics; and reports grants from US Department of Education/National Institute on Disability and Rehabilitation Research, the National Institute on Disability, Independent Living, and Rehabilitation Research, US NIH/National Institute of Arthritis and Musculoskeletal and Skin Diseases, $\mathrm{NIH} /$ National Institute of Neurologic Disorders and Stroke, US Department of Defense, and Parent Project Muscular Dystrophy US. K. Vandenborne has received grants from NIH National Institute of Arthritis and Musculoskeletal and Skin Diseases/National Institute of Neurologic Disorders and Stroke, Parent Project Muscular Dystrophy, and the Muscular Dystrophy Association. She has also received funding from ltalfarmaco SpA, Sarepta Therapeutics, Summit Therapeutics plc, Catabasis Pharmaceuticals, Pfizer Inc, ldera Pharmaceuticals, Bristol-Myers Squibb, and Eli Lilly through grant awards to the University of Florida. D. Miller reports no disclosures. S.J. Ward manages the cTAP and has received funding from the membership of cTAP to facilitate this study. E. Mercuri has served on clinical steering committees and/or as a consultant for Italfarmaco SpA, PTC Therapeutics, Prosensa, Sarepta Therapeutics, Santhera Pharmaceuticals, and BioMarin Pharmaceutical, and has served as site investigator for GlaxoSmithKline, Prosensa, BioMarin Pharmaceutical, Italfarmaco SpA, Pfizer Inc, Sarepta Therapeutics, Santhera Pharmaceuticals, Roche, and Eli Lilly. Go to Neurology.org/ $\mathrm{N}$ for full disclosures.

\section{Publication history}

Received by Neurology October 10, 2019. Accepted in final form March 6, 2020.
Appendix 1 Authors

\begin{tabular}{lll}
\hline Name & Location & Contribution \\
\hline Nathalie & University Hospitals & Designed and \\
Goemans, MD & Leuven, Belgium & $\begin{array}{l}\text { conceptualized } \\
\text { study, data } \\
\text { collection, } \\
\text { interpretation of } \\
\end{array}$ \\
& results, provided \\
& critical revision of \\
& manuscript \\
& \\
&
\end{tabular}

\begin{tabular}{lll}
\hline James & Analysis Group, Inc, & Designed and \\
Signorovitch, & Boston, MA & conceptualized study, \\
PhD & & performed statistical \\
& analyses, interpretation \\
& of results, drafted the \\
& manuscript, provided \\
& critical revision of \\
& manuscript
\end{tabular}

\begin{tabular}{lll}
\hline Gautam & Analysis Group, Inc, & Designed and \\
Sajeev, ScD & Boston, MA & conceptualized study, \\
& performed statistical \\
& analyses, interpretation \\
& of results, drafted the \\
& manuscript, provided \\
& critical revision of \\
& manuscript
\end{tabular}

Zhiwen Yao, Analysis Group, Inc, Designed and

BA Boston, MA conceptualized study,
performed statistical analyses, interpretation of results, provided critical revision of manuscript

\begin{tabular}{lll}
\hline Heather & Children's National & $\begin{array}{l}\text { Designed and } \\
\text { Gordish- }\end{array}$ \\
$\begin{array}{l}\text { Medical Center, Research } \\
\text { conceptualized study, } \\
\text { PhD }\end{array}$ & Center for Genetic & $\begin{array}{l}\text { performed statistical } \\
\text { analyses, interpretation } \\
\text { of results, provided } \\
\text { critical revision of } \\
\text { manuscript }\end{array}$ \\
& DC & \\
& & \\
\hline
\end{tabular}

\begin{tabular}{lll}
\hline Craig M. & University of California, & Designed and \\
McDonald, MD & Davis, Sacramento & $\begin{array}{l}\text { conceptualized study, } \\
\text { data collection, } \\
\end{array}$ \\
& $\begin{array}{l}\text { interpretation of results, } \\
\text { provided critical revision } \\
\text { of manuscript }\end{array}$ \\
\end{tabular}

\begin{tabular}{|c|c|c|}
\hline $\begin{array}{l}\text { Krista } \\
\text { Vandenborne, } \\
\text { PhD }\end{array}$ & $\begin{array}{l}\text { University of Florida, } \\
\text { Gainesville }\end{array}$ & $\begin{array}{l}\text { Designed and } \\
\text { conceptualized study, } \\
\text { data collection, } \\
\text { interpretation of results, } \\
\text { provided critical revision } \\
\text { of manuscript }\end{array}$ \\
\hline
\end{tabular}

\begin{tabular}{lll}
\hline Debra Miller, & CureDuchenne, Newport & Designed and \\
BA & Beach, CA & conceptualized study, \\
& & interpretation of results, \\
& provided critical revision \\
& of manuscript
\end{tabular}

\begin{tabular}{lll}
\hline Susan J. Ward, & Collaborative Trajectory & Designed and \\
PhD & Analysis Project, & conceptualized study, \\
& Cambridge, MA & interpretation of results, \\
& drafted the manuscript, \\
& provided critical revision \\
& of manuscript
\end{tabular}

Eugenio Fondaione Policlinico Designed and

Mercuri, MD Gemelli, IRCCS, Catholic conceptualized study, University, Rome, Italy data collection, interpretation of results, provided critical revision of manuscript 


\section{Appendix 2 Coinvestigators}

Coinvestigators are listed at Iww.com/WNL/B155

\section{References}

1. McDonald CM, Henricson EK, Han JJ, et al. The 6-minute walk test as a new outcome measure in Duchenne muscular dystrophy. Muscle Nerve 2010;41:500-510.

2. US Food and Drug Administration, Center for Drug Evaluation and Research. Dystrophy and related dystrophinopathies: developing drugs for treatment (guidance for industry). 2018. Available at: fda.gov/downloads/Drugs/GuidanceComplianceRegulatoryInformation/Guidances/UCM450229.pdf. Accessed June 27, 2018.

3. US Food and Drug Administration. FDA Briefing Document: Peripheral and Central Nervous System: Drugs Advisory Committee Meeting, April 25, 2016. NDA 206488 Eteplirsen. Available at: fda.gov/downloads/advisorycommittees/committeesmeetingmaterials/drugs/peripheralandcentralnervoussystemdrugsadvisorycommittee/ ucm497063.pdf. Accessed November 17, 2018.

4. ICH Expert Working Group. Choice of control group and related issues in clinical trials E10. 2000. Available at: ema.europa.eu/en/ich-e10-choice-control-group-clinical-trials. Accessed December 20, 2019.

5. Pocock SJ. The combination of randomized and historical controls in clinical trials. J Chronic Dis 1976;29:175-188.

6. Alfano L, Lowes L, Berry K, Flanigan K, Cripe L, Mendell J. Role of motivation on performance of the 6-minute walk test in boys with Duchenne muscular dystrophy: J5. Dev Med Child Neurol 2015;57:57-58.

7. American Thoracic Society. ATS statement: guidelines for the six-minute walk test. Am J Respir Crit Care Med 2002;166:111-117.

8. Victor RG, Sweeney HL, Finkel R, et al. A phase 3 randomized placebo-controlled trial of tadalafil for Duchenne muscular dystrophy. Neurology 2017;89:1811-1820.

9. Bushby K, Finkel R, Wong B, et al. Ataluren treatment of patients with nonsense mutation dystrophinopathy. Muscle Nerve 2014;50:477-487.

10. McDonald CM, Campbell C, Torricelli RE, et al. Ataluren in patients with nonsense mutation Duchenne muscular dystrophy (ACT DMD): a multicentre, randomised, double-blind, placebo-controlled, phase 3 trial. Lancet 2017;390:1489-1498.

11. Voit T, Topaloglu H, Straub V, et al. Safety and efficacy of drisapersen for the treatment of Duchenne muscular dystrophy (DEMAND II): an exploratory, randomised, placebo-controlled phase 2 study. Lancet Neurol 2014;13:987-996.

12. The Cooperative International Neuromuscular Research Group website. Available at: cinrgresearch.org/. Accessed July 9, 2018.

13. McDonald CM, Henricson EK, Abresch RT, et al. The Cooperative International Neuromuscular Research Group Duchenne Natural History Study: a longitudinal investigation in the era of glucocorticoid therapy: design of protocol and the methods used. Muscle Nerve 2013;48:32-54.

14. Henricson EK, Abresch RT, Cnaan A, et al. The Cooperative International Neuromuscular Research Group Duchenne Natural History Study: glucocorticoid treatment preserves clinically meaningful functional milestones and reduces rate of disease progression as measured by manual muscle testing and other commonly used clinical trial outcome measures. Muscle Nerve 2013;48:55-67.

15. ImagingDMD website. Available at: imagingdmd.org/. Accessed August 26, 2019.

16. Zeger SL, Liang KY, Albert PS. Models for longitudinal data: a generalized estimating equation approach. Biometrics 1988;44:1049-1060.

17. Benjamini $\mathrm{Y}$, Hochberg Y. Controlling the false discovery rate: a practical and powerful approach to multiple testing. J R Statist Soc B 1995;57:289-300.

18. Goemans N, Vanden Hauwe M, Signorovitch J, Swallow E, Song J; Collaborative Trajectory Analysis Project. Individualized prediction of changes in 6-minute walk distance for patients with Duchenne muscular dystrophy. PLoS One 2016;11: e0164684.
19. Bushby K, Finkel R, Birnkrant DJ, et al. Diagnosis and management of Duchenne muscular dystrophy, part 2: implementation of multidisciplinary care. Lancet Neurol 2010;9:177-189.

20. Bushby K, Finkel R, Birnkrant DJ, et al. Diagnosis and management of Duchenne muscular dystrophy, part 1: diagnosis, and pharmacological and psychosocial management. Lancet Neurol 2010;9:77-93.

21. Jarow JP, LaVange L, Woodcock J. Multidimensional evidence generation and FDA regulatory decision making: defining and using "real-world" data. JAMA 2017;318: 703-704.

22. Sherman RE, Anderson SA, Dal Pan GJ, et al. Real-world evidence: what is it and what can it tell us? N Engl J Med 2016;375:2293-2297.

23. US Food and Drug Administration. Framework for FDA's real-world evidence program. 2018. Available at: fda.gov/media/120060/download. Accessed September 27, 2019.

24. US Food and Drug Administration. Submitting documents using real-world data and real-world evidence to FDA for drugs and biologics: draft guidance for industry. 2019. Available at: fda.gov/media/124795/download. Accessed May 6, 2019.

25. Eichler HG, Bloechl-Daum B, Broich K, et al. Data rich, information poor: can we use electronic health records to create a learning healthcare system for pharmaceuticals? Clin Pharmacol Ther 2019;105:912-922.

26. Eichler H. Real world evidence (RWE): an introduction; how is it relevant for the medicines regulatory system? 2018. Available at: ema.europa.eu/documents/presentation/presentation-real-world-evidence-rwe-introduction-how-it-relevant-medicines-regulatory-system-emas_en.pdf. Accessed April 17, 2018.

27. Moseley J. Regulatory perspective on real world evidence (RWE) in scientific advice. European Medicines Agency; 2018.Available at: https://www.ema.europa.eu/en/ documents/presentation/presentation-regulatory-perspective-real-world-evidencerwe-scientific-advice-emas-pcwp-hcpwp-joint_en.pdf. Accessed April 17, 2018.

28. US Food and Drug Administration. FDA approves first treatment for a form of Batten disease. 2017. Available at: fda.gov/newsevents/newsroom/pressannouncements/ ucm555613.htm. Accessed October 5, 2018.

29. US Food and Drug Administration. Drug approval package: Myozyme (alglucosidase alfa). 2006. Available at: accessdata.fda.gov/drugsatfda_docs/nda/2006/ 125141s000_MyozymeTOC.cfm. Accessed October 5, 2018.

30. Wave Life Sciences Duchenne muscular dystrophy clinical trial selected for FDA complex innovative trial designs pilot program [press release]. January 3, 2019. Available at: https://ir.wavelifesciences.com/node/7811/pdf. Accessed January 30, 2020.

31. Bladen CL, Salgado D, Monges S, et al. The TREAT-NMD DMD global database: analysis of more than 7,000 Duchenne muscular dystrophy mutations. Hum Mutat 2015;36:395-402.

32. Mayhew A, Cano S, Scott E, et al. Moving towards meaningful measurement: Rasch analysis of the North Star Ambulatory Assessment in Duchenne muscular dystrophy. Dev Med Child Neurol 2011;53:535-542.

33. Scott E, Eagle M, Mayhew A, et al. Development of a functional assessment scale for ambulatory boys with Duchenne muscular dystrophy. Physiother Res Int 2012;17: 101-109.

34. Mayhew A, Mazzone ES, Eagle M, et al. Development of the performance of the Upper Limb module for Duchenne muscular dystrophy. Dev Med Child Neurol 2013; 55:1038-1045.

35. Finder J, Mayer OH, Sheehan D, et al. Pulmonary endpoints in Duchenne muscular dystrophy: a workshop summary. Am J Respir Crit Care Med 2017;196:512-519.

36. Han B, Zhan J, John Zhong Z, Liu D, Lindborg S. Covariate-adjusted borrowing of historical control data in randomized clinical trials. Pharm Stat 2017;16:296-308.

37. Hobbs BP, Carlin BP, Mandrekar SJ, Sargent DJ. Hierarchical commensurate and power prior models for adaptive incorporation of historical information in clinical trials. Biometrics 2011;67:1047-1056.

38. Viele K, Berry S, Neuenschwander B, et al. Use of historical control data for assessing treatment effects in clinical trials. Pharm Stat 2014;13:41-54.

39. Austin PC. An introduction to propensity score methods for reducing the effects of confounding in observational studies. Multivariate Behav Res 2011;46:399-424. 


\section{Neurology}

\section{Suitability of external controls for drug evaluation in Duchenne muscular dystrophy \\ Nathalie Goemans, James Signorovitch, Gautam Sajeev, et al.}

Neurology 2020;95;e1381-e1391 Published Online before print July 1, 2020

DOI 10.1212/WNL.0000000000010170

This information is current as of July 1, 2020

\section{Updated Information \& Services}

References

Citations

Subspecialty Collections

Permissions \& Licensing

Reprints including high resolution figures, can be found at: http://n.neurology.org/content/95/10/e1381.full

This article cites 27 articles, 1 of which you can access for free at: http://n.neurology.org/content/95/10/e1381.full\#ref-list-1

This article has been cited by 1 HighWire-hosted articles: http://n.neurology.org/content/95/10/e1381.full\#\#otherarticles

This article, along with others on similar topics, appears in the following collection(s):

All Clinical Neurology

http://n.neurology.org/cgi/collection/all_clinical_neurology

All Neuromuscular Disease

http://n.neurology.org/cgi/collection/all_neuromuscular_disease

All Pediatric

http://n.neurology.org/cgi/collection/all_pediatric

Natural history studies (prognosis)

http://n.neurology.org/cgi/collection/natural_history_studies_prognosis

Information about reproducing this article in parts (figures,tables) or in its entirety can be found online at:

http://www.neurology.org/about/about_the_journal\#permissions

Information about ordering reprints can be found online:

http://n.neurology.org/subscribers/advertise

Neurology ${ }^{\circledR}$ is the official journal of the American Academy of Neurology. Published continuously since 1951, it is now a weekly with 48 issues per year. Copyright Copyright ( 2020 The Author(s). Published by Wolters Kluwer Health, Inc. on behalf of the American Academy of Neurology.. All rights reserved. Print ISSN: 0028-3878. Online ISSN: 1526-632X.

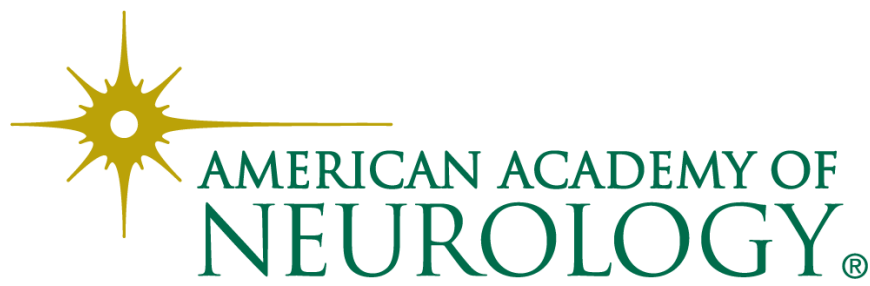

